\title{
AVALIAÇÃO DE SISTEMA ALTERNATIVO DE AUTOMAÇÃO DA IRRIGAÇÃO DO FEIJOEIRO EM CASA DE VEGETAÇÃ̃O
}

\author{
TADEU M. DE QUEIROZ ${ }^{2}$, JACINTO DE A. CARVALHO ${ }^{3}$, GIOVANNI F. RABELO ${ }^{4}$, \\ MESSIAS J. B. ANDRADE ${ }^{5}$
}

\begin{abstract}
RESUMO: O presente trabalho teve por objetivo avaliar um controlador alternativo para o manejo automático de sistemas de irrigação com tensiômetros adaptados. Cultivou-se o feijoeiro comum (Phaseolus vulgaris L.) submetido a quatro níveis de déficit hídrico $(\Psi)(15 ; 30 ; 45$ e $60 \mathrm{kPa})$ e três métodos de manejo da irrigação (M), sendo dois automatizados, utilizando tensiômetros com vacuômetro de mercúrio $(\mathrm{Hg})$ e tensiômetros com vacuômetro de Bourdon $(\mathrm{Vc})$, ambos adaptados, e o terceiro manejo, convencional, utilizando tensímetro portátil de leitura digital (Ts). Foi avaliado o funcionamento do controlador, a partir do volume de água aplicado e número de acionamentos, a produtividade de grãos e a eficiência de uso da água. Observou-se que tanto o rendimento quanto a eficiência de uso da água não foram afetados pelos métodos de manejo de irrigação. A variável volume de água aplicado foi afetada tanto pelo método (M) quanto pelas tensões $(\Psi)$ e pela interação (M x $\Psi)$. Apesar das falhas de operação apresentadas pelo tensiômetro de Bourdon adaptado, o controlador aplicou água no momento e na quantidade certa.
\end{abstract}

PALAVRAS-CHAVE: manejo de irrigação, tensiômetro, Phaseolus vulgaris L.

\section{EVALUATION OF AN ALTERNATIVE IRRIGATION AUTOMATION SYSTEM FOR COMMON BEAN IN GREENHOUSE}

\begin{abstract}
The present work aimed at evaluating an alternative controller for automatic irrigation management systems with adapted tensiometers. Common bean (Phaseolus vulgaris L.) was cultivated under four levels of water deficit $(\Psi)(15 ; 30 ; 45$ and $60 \mathrm{kPa})$ and three irrigation management methods $(\mathrm{M})$, two of them automated using tensiometers with a mercury vacuum meter $(\mathrm{Hg})$ and tensiometers with a Bourdon vacuum meter $(\mathrm{Vc})$, both adapted, and the third using conventional management with a portable digital tensiometer (Ts). The controller's operation was evaluated considering the applied volume, number of times the system started, yield and water use efficiency. It was observed that both yield and water use efficiency was not affected by the irrigation methods (5\% of probability). The variable applied volume was affected ( $1 \%$ of probability) by the methods $(\mathrm{M})$ and by the tensions $(\Psi)$ as well as by their interaction $(\mathrm{Mx} \Psi)$. Despite operating problems presented by the adapted Bourdon tensiometer/Bourdon-type tensiometer, the controller applied the right amount of water at the right time.
\end{abstract}

KEYWORDS: irrigation management, tensiometer, Phaseolus vulgaris L.

\footnotetext{
${ }^{1}$ Extraído da dissertação de Mestrado do primeiro autor. Projeto financiado pela CAPES.

${ }^{2}$ Eng $^{\mathrm{O}}$ Agrícola, doutorando em Irrigação e Drenagem, Escola Superior de Agricultura "Luiz de Queiroz", Piracicaba - SP, Fone: (0XX19) 3402.8093, tdmqueiroz@yahoo.com.br

${ }^{3}$ Eng ${ }^{-}$Agrícola, Prof. Doutor, Departamento de Engenharia, DEG/UFLA, Lavras - MG.

${ }^{4}$ Eng $^{\mathrm{O}}$ Eletricista, Prof. Doutor, Departamento de Engenharia, DEG/UFLA, Lavras - MG.

${ }^{5}$ Eng ${ }^{\text {o }}$ Agrônomo, Prof. Doutor, Departamento de Agricultura, DAG/UFLA, Lavras - MG.

Recebido pelo Conselho Editorial em: 9-3-2004

Aprovado pelo Conselho Editorial em: 23-8-2005
} 


\section{INTRODUÇÃO}

Em algumas regiões do Brasil, os recursos hídricos são escassos, requerendo estudos criteriosos para a orientação com relação ao uso mais eficiente da água. A irrigação é uma alternativa tecnológica para contornar o problema hídrico, visando a assegurar o aumento da produtividade, tanto em quantidade como em qualidade dos produtos (GOMIDE, 2002).

Tanto o excesso quanto a falta de água são fatores que afetam, de maneira marcante, o rendimento das lavouras irrigadas e, conseqüentemente, o retorno econômico desse sistema de produção (SAAD \& LIBARDI, 1994).

No Brasil, a grande maioria dos usuários da agricultura irrigada não utiliza qualquer tipo de estratégia de uso e manejo racional da água de irrigação, e o monitoramento automático para esse manejo é ainda incipiente (GOMIDE, 1998). Dentre os fatores que contribuem para a ausência do manejo de irrigação, está a metodologia que, embora disponível, ainda não foi apresentada aos produtores de forma acessível, de modo que facilite a sua adoção (SILVEIRA \& STONE, 2001).

Os sistemas de irrigação tradicionais demandam utilização de mão-de-obra para serem acionados e, além do custo de se dispor de operadores para essa função, o acionamento manual é irregular, podendo provocar a irrigação excessiva do solo, causando a lixiviação ou a irrigação deficiente, permitindo que se esgote grande parcela da água disponível armazenada entre uma irrigação e outra (MEDICE, 1997).

$\mathrm{Na}$ literatura, existem recomendações de freqüências fixas de irrigação para cada cultura. Embora possa ser prático no sentido de programação das operações, esse método acarreta déficits e excessos de água, uma vez que as condições climáticas são variáveis ano a ano. Desse modo, existe a necessidade do uso de métodos de campo que determinem, direta ou indiretamente, a disponibilidade hídrica do solo para as culturas, de acordo com as condições ambientais predominantes durante o desenvolvimento das plantas (FARIA \& COSTA, 1987).

O manejo da irrigação baseado no potencial de água no solo é a maneira mais racional de uso da água (VILLAGRA, 1988) e, para a determinação do potencial mátrico em condições de campo, o tensiômetro é o equipamento mais utilizado e recomendado (VILLAGRA, 1988 e KLEIN, 2001). Em países onde a irrigação é realizada com técnicas modernas, o tensiômetro é bastante usado, principalmente onde o controle da irrigação é automatizado (BERNARDO, 1995).

O objetivo deste trabalho foi avaliar uma metodologia alternativa de manejo automático da irrigação utilizando tensiômetros adaptados ligados a um controlador eletrônico digital.

\section{MATERIAL E MÉTODOS}

O experimento foi conduzido em casa de vegetação anexa ao Departamento de Engenharia da Universidade Federal de Lavras (DEG/UFLA), no município de Lavras, na região sul-mineira, com coordenadas geográficas $21^{\circ} 14^{\prime}$ de latitude sul, $45^{\circ}$ de longitude oeste e $918 \mathrm{~m}$ de altitude. $\mathrm{O}$ clima local é do tipo Cwa, segundo a classificação de Köeppen, o que caracteriza uma região subtropical com estiagem de inverno. Em termos anuais, a precipitação pluvial média é de 1.529,7 mm (BRASIL, 1992).

O solo utilizado (Latossolo Vermelho distroférrico argiloso, EMBRAPA, 1999) foi peneirado em malha de $2 \mathrm{~mm}^{2}$ e esterilizado.

Foi utilizado o delineamento experimental inteiramente casualizado (DIC), em esquema fatorial $3 \times 4$, totalizando 12 tratamentos, com sete repetições. Cada parcela foi composta por um vaso de $13 \mathrm{dm}^{3}$, onde foram cultivadas duas plantas de feijoeiro comum. Os tratamentos aplicados foram a combinação de três métodos de manejo da irrigação (automatizado com tensiômetro de mercúrio $(\mathrm{Hg})$, 
automatizado com tensiômetro de vacuômetro de bourdon ( $\mathrm{Vc}$ ) e convencional com tensímetro digital (Ts)), com quatro tensões de água no solo (15; 30; 45 e $60 \mathrm{kPa})$.

Para o manejo automático, adotou-se o modelo de controlador proposto por QUEIROZ et al. (2002), acionando o sistema de irrigação sempre que, pelo menos, dois dos três tensiômetros estivessem indicando o momento da irrigação. Já o manejo manual foi feito a partir das leituras de tensão realizadas uma vez ao dia $(17 \mathrm{~h})$, a partir de um tensímetro digital portátil, acionando o sistema de irrigação sempre que a tensão média de cada tratamento fosse igual ou superior à tensão-limite.

O volume de água para cada irrigação foi aquele necessário para elevar a umidade do solo à capacidade de campo $(5 \mathrm{kPa})$, utilizando-se da curva de retenção de água no solo. Os parâmetros da curva de retenção ajustados pelo modelo de GENUCHTEN (1980) foram: $\theta \mathrm{r}=0,223 ; \theta \mathrm{s}=0,763$; $\alpha=0,882 ; \mathrm{n}=1,867$, e $\mathrm{m}=0,465$.

Os tensiômetros de mercúrio e Bourdon foram adaptados para enviar um sinal elétrico ao controlador toda vez que fosse atingida a tensão-limite de cada tratamento. Na Figura 1, apresenta-se o esquema elétrico sugerido por QUEIROZ et al. (2002) para ligação dos vacuômetros ao controlador.

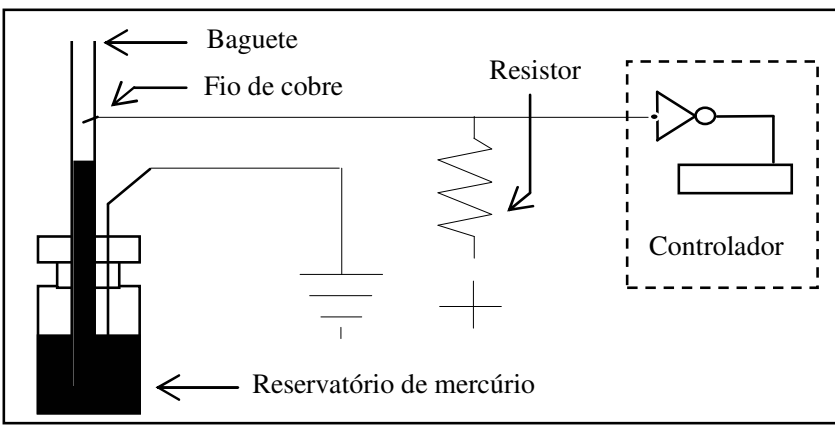

(a)

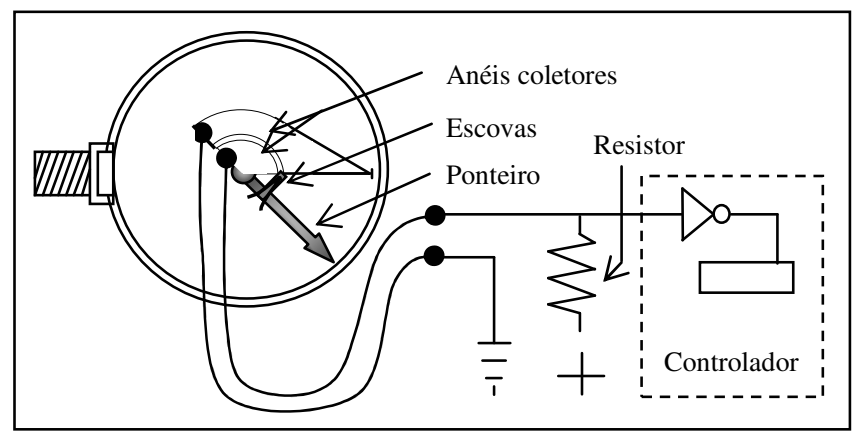

(b)

FIGURA 1. Adaptação e ligação dos tensiômetros de mercúrio (a) e bourdon (b) ao controlador, segundo QUEIROZ et al. (2002).

Nos tensiômetros com vacuômetro de mercúrio, foi inserido um fio de cobre no baguete para o contato elétrico a partir da coluna de mercúrio. Para a adaptação do vacuômetro de Bourdon, foi inserido um mecanismo, acoplado ao ponteiro, para enviar um sinal elétrico ao controlador. $\mathrm{O}$ mecanismo constitui-se de duas pistas (anéis coletores) fixadas no vidro do vacuômetro e uma escova montada sobre o ponteiro (Figura 2).

Foram utilizados três tensiômetros por tratamento, sendo um em cada vaso, instalado a $0,125 \mathrm{~m}$ de profundidade no centro do mesmo. Em cada vaso com tensiômetros, foi inserido um sistema de drenos para monitorar o escoamento do excesso de água de irrigação.

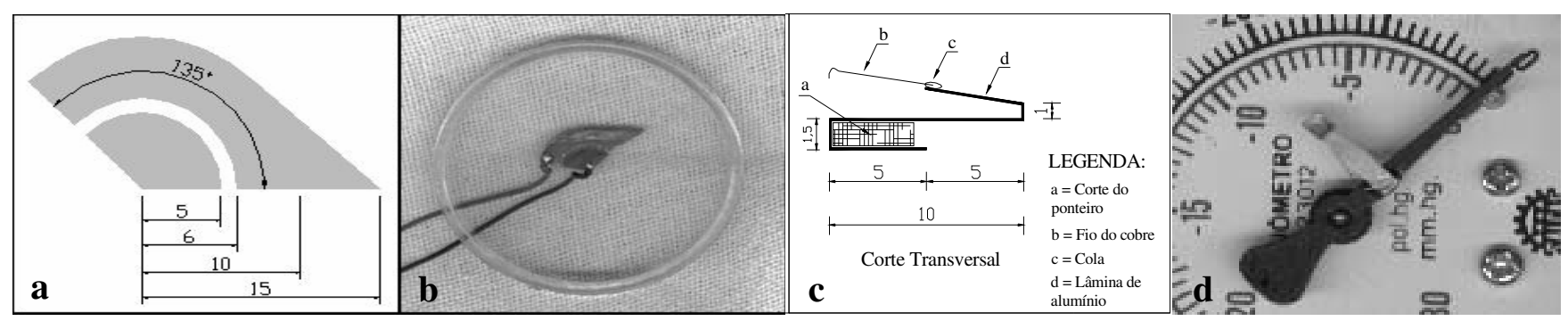

FIGURA 2. Desenho das pistas (a), vidro contendo as pistas (b), desenho esquemático da escova (c) e montagem da escova sobre o ponteiro do vacuômetro, medidas em $\mathrm{mm}$. 
Utilizou-se de uma linha lateral com oito gotejadores $\left(2,0 \mathrm{~L} \mathrm{~h}^{-1}\right)$, sendo um para cada um dos sete vasos que compunham o tratamento. O oitavo gotejador aplicava água em um recipiente para controle do volume médio aplicado e do número de acionamentos por dia. Esse recipiente foi verificado três vezes ao dia $(7 ; 12$ e 17 h). O volume médio drenado foi subtraído do volume médio aplicado em cada vaso, permitindo a estimativa do volume d'água consumido entre duas irrigações sucessivas, o que permitiu conhecer o volume consumido em cada parcela.

Foi feito um teste de uniformidade de vazão (CUV $=97 \%)$, avaliando todos os gotejadores em cada linha, o que permitiu conhecer o desvio de cada um deles em relação ao controle. Assim, foi possível estimar com precisão o volume aplicado em cada vaso.

Até o $25^{\circ}$ dia após a semeadura (DAS), as plantas receberam a mesma quantidade de água, sendo o solo mantido numa umidade próxima à capacidade de campo $(5 \mathrm{kPa})$. A partir dessa data, o controlador foi ligado e iniciou-se a aplicação dos tratamentos. Nas parcelas automatizadas, toda a água fornecida durante a fase experimental (25 DAS a 120 DAS) foi comandada pelo controlador.

Foram avaliados o funcionamento do controlador e dos tensiômetros adaptados, o volume total de água aplicado por vaso e a produtividade de grãos por planta. A eficiência de uso da água $\left(\mathrm{kg} \mathrm{m}^{-3}\right)$ foi obtida pela relação entre a produtividade de grãos por vaso (duas plantas) $(\mathrm{kg})$ e o volume de água consumido (Aplicado - Drenado) por vaso $\left(\mathrm{m}^{3}\right)$.

Os dados foram submetidos à análise de variância e teste de médias para a fonte de variação método de manejo de irrigação e regressão para a fonte de variação tensão.

\section{RESULTADOS E DISCUSSÃO}

Na Figura 3, apresenta-se o número de irrigações (acionamentos) de cada tratamento ocorrido no intervalo de 25 DAS até 120 DAS.

Observam-se comportamentos diferentes para a tensão $45 \mathrm{kPa}$ com os métodos automáticos $\mathrm{Hg}$ e Vc em relação à mesma tensão no método manual (Ts). O método $\mathrm{Hg}$, que é o padrão, foi mais sensível do que o Vc, identificando o momento da irrigação em maior número de vezes.

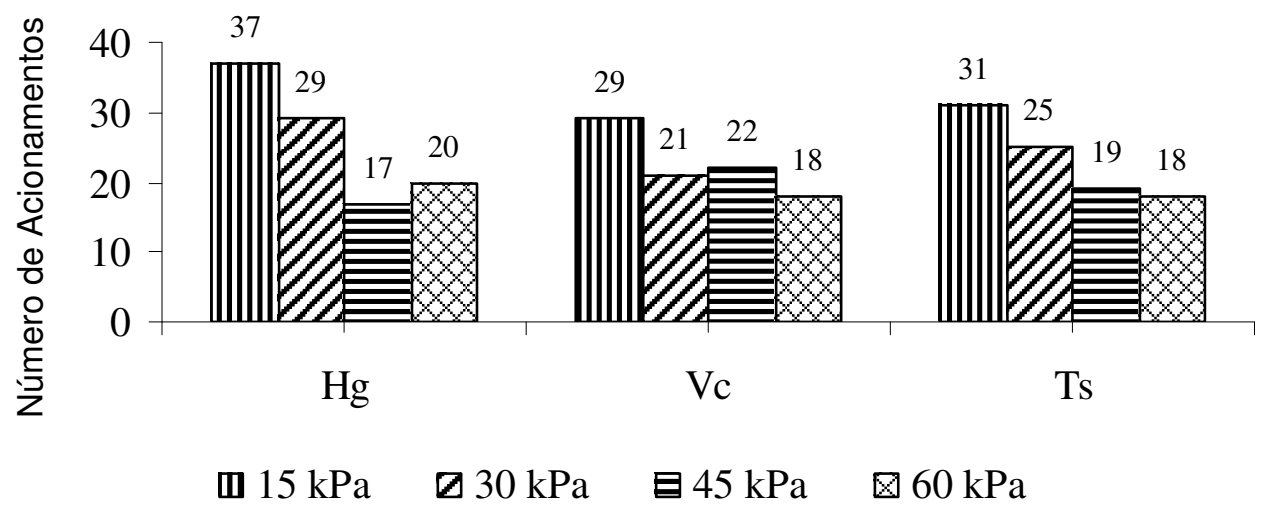

FIGURA 3. Número de acionamentos de cada tratamento.

Os tensiômetros adaptados do método Vc apresentaram falhas no acionamento, provocando a repetição do ciclo de irrigação, conforme Figura 4.

Observa-se que houve maior tendência de falha na tensão de $45 \mathrm{kPa}$, o que pode estar relacionado com o equilíbrio da força de atrito do sensor no contato escova-pistas e a força da mola do mecanismo interno dos vacuômetros de Bourdon. Isso indica que melhorias devem ser feitas no 
mecanismo de contato elétrico do vacuômetro para que o funcionamento desse seja mais preciso e confiável.

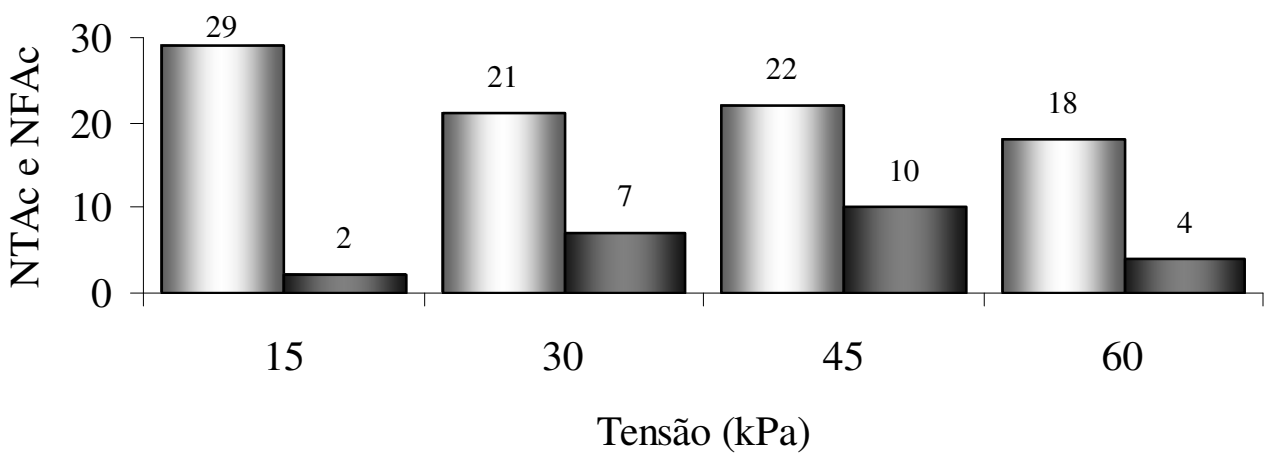

$\square$ NTAc $\quad \square$ NFAc

FIGURA 4. Número total de acionamentos (NTAc) e número de falhas no acionamento (NFAc) para as quatro tensões no método $\mathrm{Vc}$.

Observa-se, na Figura 5 (a, b, c, d), que o método Vc, quando não falha, se aproxima do método Hg. Resultado semelhante foi encontrado por BRASIL et al. (2003), que avaliaram a precisão, exatidão e resolução de vacuômetros de Bourdon (metálico) da marca FAMABRÁS, modelo FL-62/1, com escala de 0 a $100 \mathrm{kPa}$, e concluíram que os mesmos são instrumentos precisos, com alto grau de exatidão e que possuem resolução equivalente ao tensiômetro de $\mathrm{Hg}$.

Os picos observados na curva representativa do método Vc indicam a ocorrência de falhas, em que se observou a repetição do ciclo de irrigação, que resultou na aplicação do dobro da água necessária. O pico ascendente do método $\mathrm{Hg}$, aos $105 \mathrm{DAS}$, submetido à tensão de $15 \mathrm{kPa}$, foi devido à repetição normal da irrigação, caracterizando maior demanda de água das plantas desse tratamento. O volume aplicado em cada irrigação foi aproximadamente idêntico, salvo quando houve falhas no mecanismo de acionamento do sensor dos vacuômetros de Bourdon. O volume aplicado no método Ts foi inexato devido à imprecisão na identificação do momento da irrigação pelo método de manejo manual, no qual as medidas da tensão matricial foram feitas somente uma vez por dia.

$\mathrm{Na}$ Tabela 1, apresenta-se o resumo da análise de variância para os dados de volume total de água aplicado, produtividade de grãos e eficiência de uso da água. O volume aplicado foi significativamente diferente para a fonte de variação método de manejo de irrigação, provavelmente, devido ao grande número de falhas ocorridas no método Vc, que provocou excesso de irrigação. As variáveis produtividade de grãos e eficiência de uso da água não foram afetadas pelos métodos de manejo, mostrando, inclusive, que o manejo automático pode substituir o manual sem prejuízo na produção ou consumo excessivo de água. SANTOS (2002), trabalhando com sistema de controle similar na irrigação do pepino caipira, encontrou resultados semelhantes, confirmando a eficiência desse método de manejo da irrigação.

Na Tabela 2, apresenta-se o resultado do teste de médias para o volume de água aplicado em cada tensão, em que se verifica que houve influência do tipo de método de manejo de irrigação nas difentes tensões. As diferenças observadas no volume de água aplicado, em cada tensão, pelo método Vc, são explicadas pelas falhas ocorridas. Os métodos $\mathrm{Hg}$ e Ts diferem-se, em relação ao volume aplicado, somente para a tensão de $30 \mathrm{kPa}$, provavelmente devido à maior sensibilidade do feijoeiro cultivado nas condições em que se deu o experimento, na tensão de $30 \mathrm{kPa}$. Para as demais tensões, não há diferença entre os métodos $\mathrm{Hg}$ e Ts, mostrando que pode ser utilizado o controlador alternativo proposto com tensiômetros de mercúrio em substituição ao manejo covencional. 
(a)

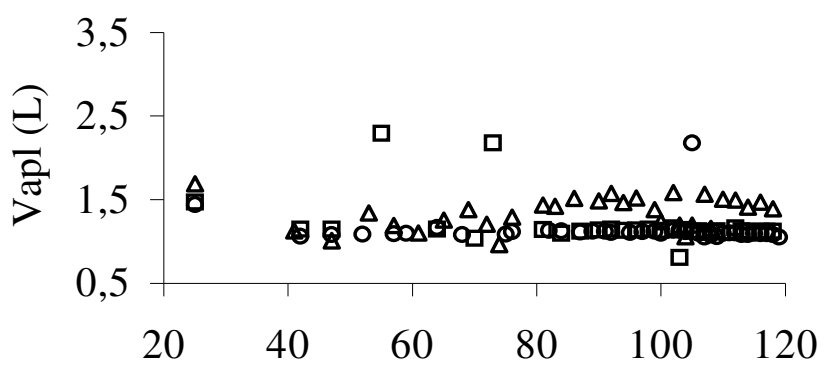

Dias Após Semeadura

$\circ \mathrm{Hg}$

$\square \mathrm{Vc}$

$\Delta \mathrm{Ts}$

(c)

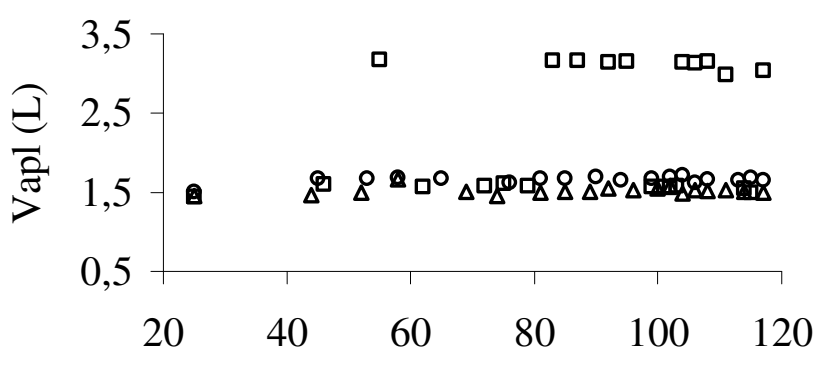

Dias Após Semeadura

- $\mathrm{Hg} \quad \mathrm{Vc} \Delta \mathrm{Ts}$ (b)

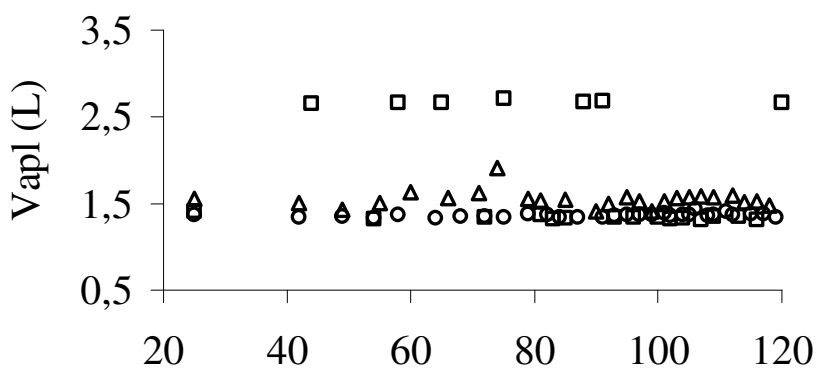

Dias Após Semeadura

$\circ \mathrm{Hg} \quad \square \mathrm{Vc} \Delta \mathrm{Ts}$

(d)

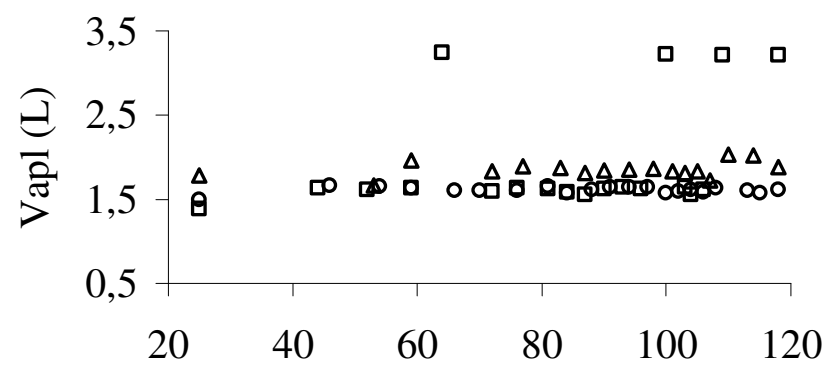

Dias Após Semeadura

- $\mathrm{Hg} \quad \mathrm{Vc} \Delta \mathrm{Ts}$

FIGURA 5. Volume de água aplicado (Vapl, em L) pelos três métodos de manejo de irrigação, nas tensões de $15 \mathrm{kPa}$ (a), $30 \mathrm{kPa}(\mathrm{b}), 45 \mathrm{kPa}$ (c) e $60 \mathrm{kPa}(\mathrm{d})$.

TABELA 1. Resumo da análise de variância dos dados de volume total aplicado por vaso (Vapl), rendimento de grãos (RGr) e eficiência de uso da água (EU).

\begin{tabular}{|c|c|c|c|c|}
\hline \multirow{2}{*}{ Fontes de variação } & \multirow{2}{*}{$\begin{array}{l}\text { Graus de } \\
\text { Liberdade }\end{array}$} & \multicolumn{3}{|c|}{ Quadrado Médio } \\
\hline & & Vapl (L) & RGr (g planta $\left.{ }^{-1}\right)$ & $\mathrm{EU}\left(\mathrm{kg} \mathrm{m}^{-3}\right)$ \\
\hline Método de Irrigação (M) & 2 & $129,1430 * *$ & $28,166^{\mathrm{NS}}$ & $0,048^{\mathrm{NS}}$ \\
\hline Tensão $(\Psi)$ & 3 & $138,8855^{* *}$ & $55,46 * *$ & $0,066^{\mathrm{NS}}$ \\
\hline Interação (M x $\Psi)$ & 6 & $366,2476 * *$ & $83,94 * *$ & $0,144 * *$ \\
\hline Resíduo & 72 & 1,1667 & 9,80 & 0,035 \\
\hline Média Geral & & 30,06 & 14,99 & 0,884 \\
\hline C.V. $(\%)$ & & 2,91 & 20,88 & 21,14 \\
\hline
\end{tabular}

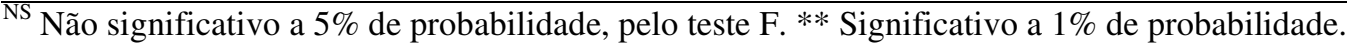

TABELA 2. Comparação de médias para volume de água aplicado por vaso (L), em cada tratamento, pelo teste de Tukey, a 5\% de probabilidade.

\begin{tabular}{ccccc}
\hline \multirow{2}{*}{ Métodos de Manejo } & \multicolumn{4}{c}{ Tensão Matricial (kPa) } \\
\cline { 2 - 5 } & 15 & 30 & 45 & 60 \\
\hline $\mathrm{Hg}$ & $41,87 \mathrm{~b}$ & $41,08 \mathrm{~b}$ & $28,83 \mathrm{a}$ & $32,60 \mathrm{a}$ \\
$\mathrm{Vc}$ & $34,69 \mathrm{a}$ & $37,58 \mathrm{a}$ & $50,20 \mathrm{~b}$ & $35,61 \mathrm{~b}$ \\
$\mathrm{Ts}$ & $41,08 \mathrm{~b}$ & $38,84 \mathrm{a}$ & $28,52 \mathrm{a}$ & $33,81 \mathrm{a}$ \\
\hline Diferença Mínima Significativa (DMS) & 1,382 & 1,382 & 1,382 & 1,382 \\
\hline
\end{tabular}

Médias seguidas da mestra letra, na vertical, não diferem estatisticamente entre si, a 5\% de probabilidade. 
Na Figura 6, apresenta-se o resultado da análise de regressão para os dados de volume total aplicado por vaso.

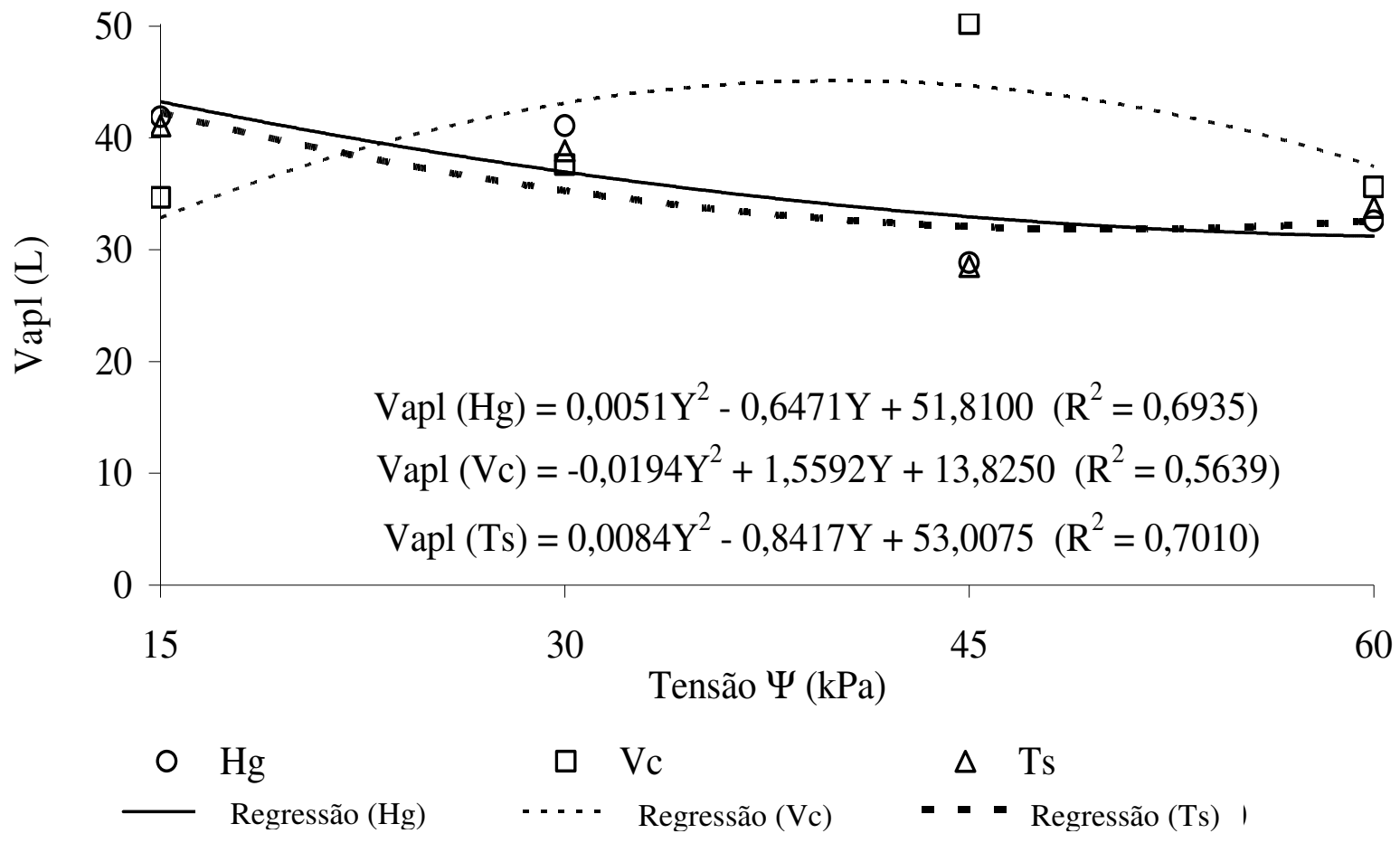

FIGURA 6. Volume total de água aplicado por vaso (L), nos três métodos de manejo, em função da tensão.

Observa-se tendência de igualdade entre os métodos $\mathrm{Hg}$ e $\mathrm{Ts}$, confirmando a eficiência do controle automatizado com tensiômetros de mercúrio e também a eficiência do controlador utilizado. O comportamento diferenciado do método Vc pode ser explicado pelo grande número de falhas detectadas, principalmente no tratamento $\mathrm{Vc}-45$.

Na Tabela 3, apresenta-se o resultado do teste de médias para a produtividade de grãos. Observase diferença entre os métodos apenas nas tensões de 45 e $60 \mathrm{kPa}$. Na tensão de $45 \mathrm{kPa}$, a diferença é devida ao maior volume aplicado pelo método Vc. Para as tensões de 15 e $30 \mathrm{kPa}$, o método não afetou a produtividade de grãos. Esse resultado confirma a eficiência do controlador na aplicação de água no momento e na quantidade certa, determinado pela sensibilidade do tensiômetro.

TABELA 3. Comparação de médias para a produtividade de grãos (g planta $\left.{ }^{-1}\right)$, pelo teste de Tukey, a $5 \%$ de probabilidade.

\begin{tabular}{crrrr}
\hline \multirow{2}{*}{ Métodos de Manejo } & \multicolumn{4}{c}{ Tensão Matricial (kPa) } \\
\cline { 2 - 5 } & 15 & 30 & 45 & 60 \\
\hline $\mathrm{Hg}$ & $16,58 \mathrm{a}$ & $17,42 \mathrm{a}$ & $9,17 \mathrm{a}$ & $16,25 \mathrm{~b}$ \\
$\mathrm{Vc}$ & $14,27 \mathrm{a}$ & $16,29 \mathrm{a}$ & $19,74 \mathrm{~b}$ & $13,90 \mathrm{ab}$ \\
Ts & $17,24 \mathrm{a}$ & $16,29 \mathrm{a}$ & $10,77 \mathrm{a}$ & $11,93 \mathrm{a}$ \\
\hline Médias & 16,03 & 16,67 & 13,23 & 14,03 \\
\hline
\end{tabular}

Médias seguidas da mestra letra, na vertical, não diferem estatisticamente entre si, a 5\% de probabilidade. 
$\mathrm{O}$ método $\mathrm{Hg}$ diferiu-se do Ts somente na tensão de $60 \mathrm{kPa}$, em que o método de manejo automatizado (Hg-60) proporcionou melhor produtividade de grãos. Esse resultado mostra que a determinação precisa das condições de umidade do solo (manejo automatizado) pode reverter em ganhos de produção e lucratividade.

Na Figura 7, são mostradas as curvas de tendência da produtividade de grãos, em função da tensão, para os três métodos. Observa-se comportamento muito parecido com o volume aplicado, sendo diferente apenas para o método $\mathrm{Ts}$, que apresentou tendência linear decrescente para a produtividade de grãos em função do aumento do déficit hídrico. STONE et al. (1990) encontraram resultado semelhante quando cultivaram o feijoeiro submetido a diferentes tensões de água no solo.

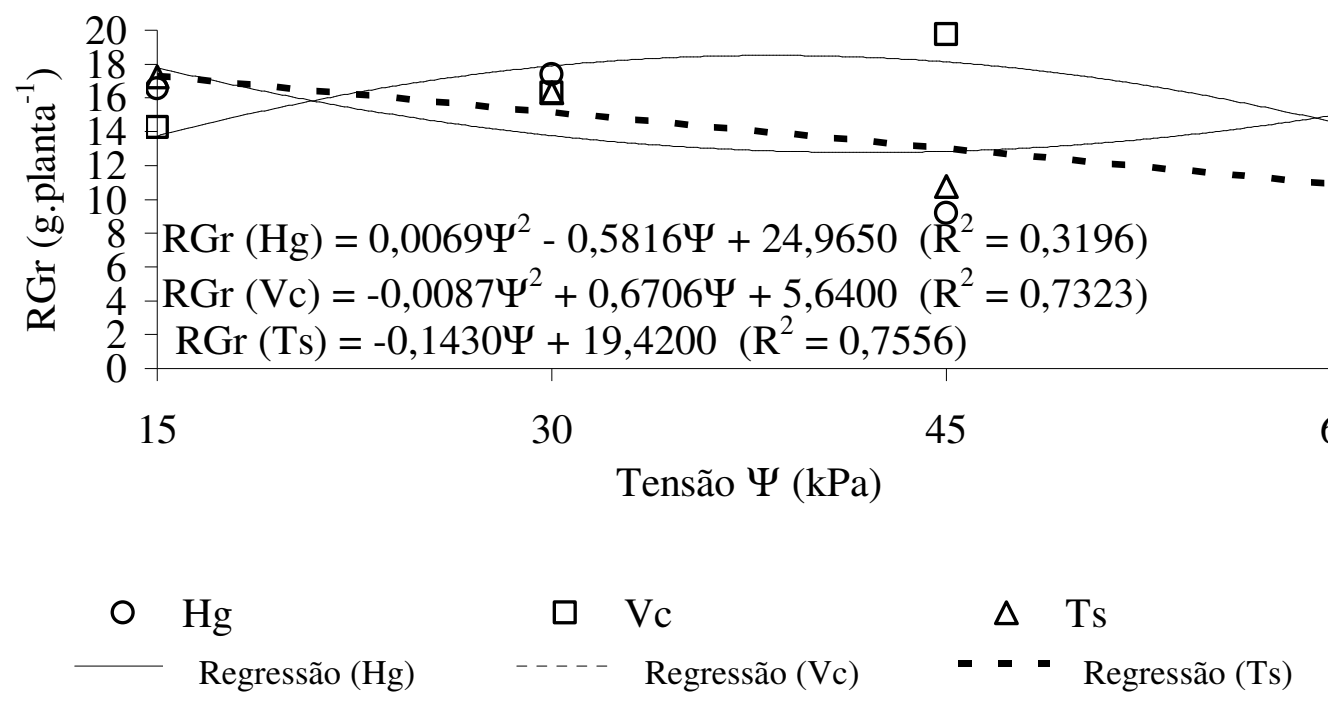

FIGURA 7. Resultado da análise de regressão para os dados de produtividade de grãos (RGr) por planta.

Em relação à eficiência de uso da água, observa-se, pela Tabela 4, que, para o feijoeiro cultivado nas tensões de 15 e $30 \mathrm{kPa}$, não há influência do método de manejo nem do tipo de tensiômetro utilizado para o manejo automático. Para a tensão de $45 \mathrm{kPa}$, o método $\mathrm{Hg}$ é estatisticamente igual ao do Ts, indicando que o método de manejo automatizado pode substituir o manual sem prejuízo ao irrigante, pois a produtividade de grãos (Tabela 3) também foi estatisticamente igual.

Nas condições em que se conduziu o experimento, a combinação que resultou em melhor eficiência de uso da água foi a tensão de $60 \mathrm{kPa}$, quando o manejo foi automatizado com tensiômetro de mercúrio.

TABELA 4. Comparação de médias, para a eficiência de uso da água $\left(\mathrm{kg} \mathrm{m}^{-3}\right)$, pelo teste de Tukey, a $5 \%$ de probabilidade.

\begin{tabular}{ccccc}
\hline \multirow{2}{*}{ Métodos de Manejo } & \multicolumn{4}{c}{ Tensão Matricial (kPa) } \\
\cline { 2 - 5 } & 15 & 30 & 45 & 60 \\
\hline $\mathrm{Hg}$ & $0,85 \mathrm{a}$ & $0,90 \mathrm{a}$ & $0,68 \mathrm{a}$ & $1,17 \mathrm{~b}$ \\
$\mathrm{Vc}$ & $0,86 \mathrm{a}$ & $1,00 \mathrm{a}$ & $0,94 \mathrm{~b}$ & $0,86 \mathrm{a}$ \\
Ts & $0,90 \mathrm{a}$ & $0,89 \mathrm{a}$ & $0,81 \mathrm{ab}$ & $0,75 \mathrm{a}$ \\
\hline DMS & 0,24 & 0,24 & 0,24 & 0,24 \\
\hline
\end{tabular}

Médias seguidas da mestra letra, na vertical, não diferem estatisticamente entre si, a 5\% de probabilidade. 
Na Figura 8, apresenta-se a tendência de variação da eficiência de uso da água, em função da tensão, para o método $\mathrm{Hg}$, na qual se verifica um comportamento quadrático. Os modelos ajustados para os demais tratamentos não foram significativos, a $5 \%$ de probabilidade, pelo teste $\mathrm{F}$.

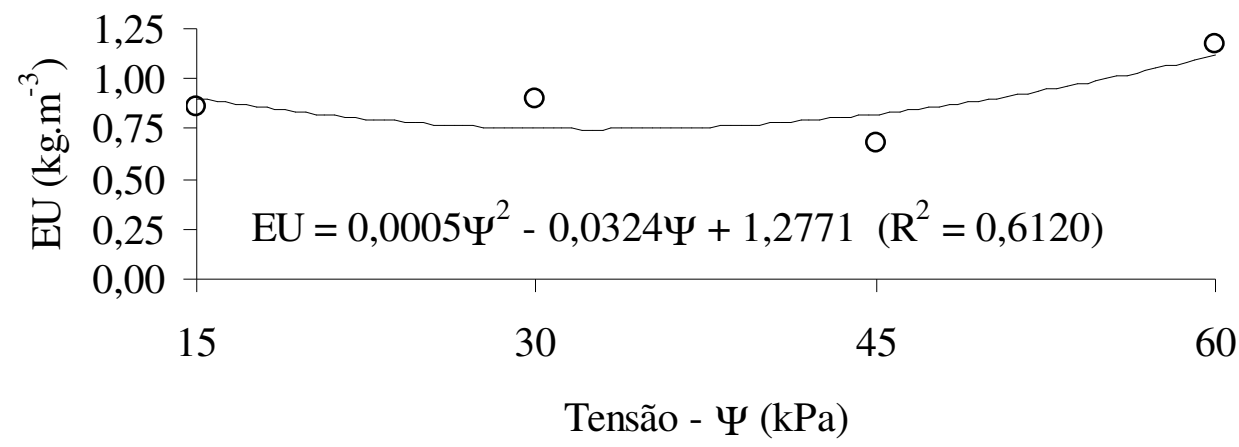

FIGURA 8. Eficiência de uso da água (EU) para o método automático (Hg), em função da tensão de água no solo.

A eficiência de uso da água é um parâmetro importante na seleção de métodos de aplicação e manejo da água de irrigação, pois indica qual a combinação que leva à maior produção com o menor consumo; entretanto, é um parâmetro muito variável. Na literatura, encontra-se citação de valores muito discrepantes.

MACEDO JUNIOR (1993), cultivando o feijoeiro em vaso, obteve maior eficiência na tensão de $500 \mathrm{kPa}\left(1,79 \mathrm{~kg} \mathrm{~m}^{-3}\right)$ para a cultivar Preto 60 dias e $200 \mathrm{kPa}\left(1,73 \mathrm{~kg} \mathrm{~m}^{-3}\right)$ para a cultivar Esal-688. HEGDE \& SRINIVAS (1989), trabalhando no intervalo de tensão entre 25 e $85 \mathrm{kPa}$, encontraram melhor eficiência para o tratamento $45 \mathrm{kPa}\left(0,44 \mathrm{~kg} \mathrm{~m}^{-3}\right)$.

\section{CONCLUSÕES}

O controlador alternativo de baixo custo utilizado mostrou-se eficiente para o manejo automático da irrigação a partir de tensiômetros.

A adaptação feita nos tensiômetros de Bourdon não foi adequada, provocando falhas no acionamento.

Pode-se recomendar o manejo automatizado com tensiômetros de mercúrio em substituição ao método convencional.

\section{AGRADECIMENTOS}

À Professora Janice Guedes de Carvalho, pela colaboração na recomendação das correções nutricionais das plantas durante o experimento.

\section{REFERÊNCIAS}

BERNARDO, S. Manual de irrigação. 4.ed. Viçosa - MG: UFV, Imprensa Universitária, 1995. 657 p.

BRASIL, R.P.C.; CASARINI, E.; FOLEGATTI, M.V.; VASQUEZ, M.A.N. Avaliação de vacuômetros de Bourdon utilizados em tensiômetros no manejo da irrigação. In: CONGRESSO BRASILEIRO DE ENGENHARIA AGRÍCOLA, 32., 2002, Goiânia. Anais... Goiânia: Sociedade Brasileira de Engenharia Agrícola, 2003. 1 CD-ROM. 
BRASIL. Ministério da Agricultura. Normais climatológicas: 1961-1990. Brasília:

EMBRAPA/DNMET, 1992. 84 p.

EMPRESA BRASILEIRA DE PESQUISA AGROPECUÁRIA. Centro Nacional de Pesquisa Agropecuária. Sistema brasileiro de classificação de solos. Rio de Janeiro, 1999. 412 p.

FARIA, R.T. de; COSTA, C.S. da. Tensiômetro: construção, instalação e utilização - um aparelho simples para se determinar quando irrigar. Londrina: IAPAR, 1987. 24 p. (Circular Técnica, 56).

GENUCHTEN, M.T.H. Van. A closed-form equation for predicing the hydraulic condutivity fo unsaturated soils. Soil Science Society American Journal, Madison, v.4, n.5, p.892-98, 1980.

GOMIDE, R.L. Monitoramento para manejo da irrigação: instrumentação, automação e métodos. In: CONGRESSO BRASILEIRO DE ENGENHARIA AGRÍCOLA, 27., 1998, Poços de Caldas. Anais... Lavras: Sociedade Brasileira de Engenharia Agrícola, 1998. cap.2, p.133-238.

GOMIDE, R. L. Monitoramento automático de fluxo de seiva com sondas de balanço de energia e caracterização de estresse hídrico de duas linhagens de milho (Zea mays L.). In: CONGRESSO BRASILEIRO DE ENGENHARIA AGRÍCOLA, 31., 2002, Salvador. Anais... Salvador: Sociedade Brasileira de Engenharia Agrícola, 2002. 1 CD-ROM.

HEGDE, D M.; SRINIVAS K. Effect of irrigation and nitrogen on growth, yield and water use of frenchbean. Indian Journal Agronomy, New Delhi, v.34, n.2, p.180-4, June 1989.

KLEIN, V.A. Sistema automático de irrigação. In: CONGRESSO BRASILEIRO DE ENGENHARIA AGRÍCOLA, 30, 2001, Foz do Iguaçu. Anais... Foz do Iguaçu: Sociedade Brasileira de Engenharia Agrícola, 2001. 1 CD-ROM.

MACEDO JUNIOR, E.K. Comportamento biofísico e agronômico de plantas de feijoeiro (Phaseolus vulgaris L.) submetidas a cinco níveis de tensão matricial da água no solo. 1993. 103 f. Dissertação (Mestrado em Irrigação e Drenagem) - Escola Superior de Agricultura de Lavras, Lavras, 1993.

MEDICE, L.O. Acionador automático de sistemas de irrigação. Revista da Propriedade Industrial, Rio de Janeiro, n.1399, s.p., 1997.

QUEIROZ, T.M. de; GIACOMIN, J.C.; RABELO, G.F.; BRAGA JUNIOR, R.A. Circuito eletrônico para controle automático, em malha fechada, de sistemas de irrigação através de tensiômetros. In: CONGRESSO BRASILEIRO DE ENGENHARIA AGRÍCOLA, 31., 2002, Salvador. Anais... Salvador: Sociedade Brasileira de Engenharia Agrícola, 2002. 1 CD-ROM.

SAAD, A.M.; LIBARDI, P.L. Aferição do controle da irrigação feito pelos agricultores utilizando tensiômetros de faixas. São Paulo: IPT, 1994. 14 p. (Publicação, 2147)

SANTOS, D.S. dos. Efeitos da tensão de água no solo, na cultura do pepino (Cucumis sativus L.), utilizando sistema de irrigação automatizado. 2002. 60 f. Dissertação (Mestrado em Irrigação e Drenagem) - Universidade Federal de Lavras, Lavras, 2002.

SILVEIRA, P.M.; STONE, L.F. Irrigação do feijoeiro. Santo Antônio de Goiás: Embrapa Arroz e Feijão, 2001. 230 p.

STONE, L.F.; MOREIRA, J.A.A.; SILVA, C. Efeitos da tensão da água do solo sobre a produtividade e o crescimento do feijoeiro. I. Produtividade. In: REUNIÃO SOBRE FEIJÃO IRRIGADO (GO, DF, MG, SP, RJ), 1., 1988, Goiânia. Anais... Goiânia: EMBRAPA-CNPAF, 1990. p.111.

VILLAGRA, M. de las M. Variabilidade de medidas de tensiômetro em terra roxa estruturada. 1988. 64 f. Dissertação (Mestrado em Energia Nuclear na Agricultura) - Escola Superior de Agricultura “Luiz de Queiroz", Universidade de São Paulo, Piracicaba, 1988. 